\title{
Prevalence, Trend And Determinants of Adolescent Childbearing In Burundi: A Multilevel Analysis of The 1987 To 2016-17 Burundi Demographic And Health Surveys Data.
}

Jean Claude NIBARUTA ( $\nabla$ nibajclaude@gmail.com )

Hassan First University of Settat https://orcid.org/0000-0002-9693-403X

Noureddine ELKHOUDRI

Hassan First University of Settat

Jack Edward TURMAN,jr.

Indiana University Richard M Fairbanks School of Public Health

Morad GUENNOUNI

Hassan First University of Settat

Saad ELMADANI

Hassan First University of Settat

\section{Research}

Keywords: Adolescent, childbearing, determinants, multilevel analysis, Burundi.

Posted Date: August 25th, 2021

DOI: https://doi.org/10.21203/rs.3.rs-800806/v1

License: (c) (1) This work is licensed under a Creative Commons Attribution 4.0 International License.

Read Full License

Version of Record: A version of this preprint was published at BMC Pregnancy and Childbirth on September 1st, 2022. See the published version at https://doi.org/10.1186/s12884-022-05009-y. 


\section{Abstract}

Background: Very little is known about factors influencing adolescent childbearing despite an upward trend in adolescent childbearing prevalence in Burundi, and its perceived implications on the rapid population growth and ill-health of young mothers and their babies. To adress this gap, this study aimed to examine the prevalence, trends and determinants of adolescent childbearing in Burundi.

Methods Secondary analyses of the 1987, 2010 and 2016-17 Burundi Demographic and Health Surveys (BDHS) data were conducted using STATA. Weighted samples of 731 (1987 BDHS), 2359 (2010 BDHS) and 3859 (2016-17BDHS) adolescent girls aged 15-19 years old were used for descriptive and trend analyses. Both bivariable and multivariable two-level logistic regression analyses were performed to identify the main factors associated with adolescent childbearing using only the 2016-17 BDHS data.

Results The prevalence of adolescent childbearing increased from $5.9 \%$ in 1987 to $8.3 \%$ in 2016/17. Factors such as adolescent girls aged $18-19$ years old (aOR $=5.85,95 \% \mathrm{Cl}: 3.54-9.65, p<0.001)$, adolescent illiteracy $(\mathrm{aOR}=4.18,95 \% \mathrm{Cl}: 1.88$ - 9.30, $\mathrm{p}<0.001)$, living in poor communities $(\mathrm{aOR}=2.19,95 \%$ Cl: 1.03 - 4.64, $p=0.042)$, early marriage $(a O R=9.28,95 \% \mathrm{Cl}: 3.11-27.65, p<0.001)$, lack of knowledge of any contraceptive methods ( $\mathrm{aOR}=5.33,95 \% \mathrm{Cl}: 1.48-19.16, \mathrm{p}=0.010)$, and non-use of modern contraceptive methods ( $\mathrm{aOR}=24.48,95 \% \mathrm{Cl}: 9.80-61.14), \mathrm{p}<0.001)$ were associated with higher odds of adolescent childbearing. While factors such as living in the richest household index (aOR=0.52, 95\% IC: $0.45-0.87, p=0.00)$, living in West region ( $\mathrm{aOR}=0.26,95 \% \mathrm{Cl}: 0.08-0.86, p=0.027)$ or in South region $(\mathrm{aOR}=0.31,95 \% \mathrm{Cl}: 0.10-0.96, \mathrm{p}=0.041)$ were associated with lower odds of adolescent childbearing.

Conclusion Our study found an upward trend in adolescent childbearing prevalence and there were significant variations in the odds of adolescent childbearing by some individual and community-level factors. School-and community-based intervention programs aimed at promoting girls' education, improving socioeconomic status, knowledge and utilization of contraceptives and prevention of early marriage among adolescent girls is crucial to reduce adolescent childbearing in Burundi.

\section{Plain English Summary}

Adolescent childbearing is recognized as a global public health challenge given its multiple negative consequences for both young mothers and their babies, particularly in developing countries. Therefore, a good understanding of factors influencing adolescent childbearing is crucial to meet this challenge. In Burundi, despite an upward trend in adolescent childbearing prevalence, very little is known about factors influencing adolescent childbearing. To adress this gap, this study aimed to examine the prevalence, trend and determinants of adolescent childbearing. For this purpose, Secondary analysis of the 1987, 2010 and 2016-17 Burundi Demographic and Health Survey (BDHS) data were conducted using STATA software version14.2. Weighted samples of 731 (1987 BDHS), 2359 (2010 BDHS) and 3859 (201617BDHS) adolescent girls aged 15-19 years old were used for descriptive and trend analyses. Both 
bivariable and multivariable multi-level logistic regression analyses were performed to identify the main factors associated with adolescent childbearing using only the 2016-17 BDHS data. Our findings revealed that the prevalence of adolescent childbearing increased from $5.9 \%$ in 1987 to $8.3 \%$ in 2016/17. Factors such as late adolescent age, adolescent illiteracy, household poverty or living in high community-level poverty, adolescent early marriage, lack of knowledge of any contraceptive methods, non-use of modern contraceptive methods, and living in Bujumbura Mairie were associated with higher odds of adolescent childbearing. Therefore school-and community-based intervention programs aimed at promoting girls' education, improving socioeconomic status, knowledge and utilization of contraceptives and prevention of early marriage among adolescent girls is crucial to reduce adolescent childbearing in Burundi.

\section{Introduction}

The World Health Organization (WHO) and United Nations entities define an adolescent as an individual aged 10-19 years [1,2]. Adolescent childbearing is a major global public health issue because of its many adverse health and socio-economic consequences for both young mothers and their babies, particularly in Sub-Saharan Africa (SSA) $[3,4]$. While adolescent childbearing declined significantly overall since 2004[5], significant disparities persist between and within countries and among population groups, particularly in SSA[3, 6-8]. In 2015-2020, SSA had the highest levels of adolescent childbearing, followed by Asia and Latin America and the Caribbean [6]. Almost one-fifth (18.8\%) of adolescent girls got pregnant in Africa, and a higher prevalence (21.5\%) was observed in the East African sub-region where Burundi is located [3]. Several studies state that adolescent childbearing is associated with higher maternal mortality and morbidity and adverse child outcomes including a higher prevalence of low birth weight and higher perinatal and neonatal mortality as compared to older women [3, 4, 9]. Adolescent early initiation into childbearing lengthens the reproductive period and subsequently increases a woman's lifetime fertility rate, contributing to rapid population growth [10-12].

The Burundian population is characterized by its extreme youth, with $65 \%$ under the age of 25 and almost a quarter of this growing population (23\%) are adolescents[13]. In Burundi, adolescent childbearing remains an important issue because of its perceived implications on the rapid population growth and illhealth of adolescent mothers and their babies[11]. According to the report of the latest Burundi Demographic and Health Survey (BDHS) [14], 8\% of women aged 15-19 begun childbearing, including 6 $\%$ who had at least one live birth and $2 \%$ who were pregnant with their first child. Despite a good progress in reducing maternal mortality ratio [14], a large number of adolescent girls are still dying from pregnancy and childbirth related complications. The maternal mortality rate among Burundian adolescent girls is estimated at 150 maternal deaths per 1,000 women aged 15-19 years [14]. Maternal disorders are the fourth highest cause of death among teenage mothers in Burundi[13]. Early marriage and adolescent pregnancy could lead to or aggravate anemia in mothers and result in low iron stores in the offspring[15], or in prematurity or low birth weight babies [16]. Approximately $36 \%$ of Burundian adolescent girls are anemic and $0.4 \%$ have obstetric fistula [14]. On the other hand, the infant mortality rate among adolescent girls in Burundi is estimated at 59 deaths per 1,000 live births, of which $30 \%$ are neonatal and 
$29 \%$ post-neonatal [14]. In addition, the prevalence of low birth weight is higher among adolescent mothers $(7.2 \%)$ than among women aged $20-34$ years $(4.7 \%)$ [14].

Several studies were conducted to examine the factors influencing adolescent pregnancy and motherhood in various settings. The results of these studies showed that early marriage or sexual intercourse $[4,7,9]$, illiteracy or low level of education and poverty $[3,7,9,10]$ or living in poor neighborhoods $[17,18]$, age of the adolescent $[4,10,19]$, marital status $[3,4,10]$, rural residence and geographic regions $[3,4,10,20]$ are important factors influencing adolescent childbearing. Despite an upward trend in adolescent childbearing prevalence and its perceived implications on the rapid population growth and poor health of young mothers and their babies, very little is known about factors influencing adolescent childbearing in Burundi[21-23].Only two BDHS reports[14, 24] containing information on factors influencing adolescent childbearing are available in Burundi. The results of these two surveys are limited to a few determinants of adolescent childbearing and are fully descriptive, and therefore do not make it possible to know the net effect of each of the factors influencing adolescent childbearing in the Burundian settings. To adress this gap, we aim to examine the prevalence, trend and determinants of adolescent childbearing using the 1987 to 2016-17 BDHS data.

\section{Data And Methods}

\subsection{Data sources and population}

This study used adolescent women (aged 15-19) data extracted from the three BDHS conducted in 1987[25], 2010[24] and 2016-2017 [14] for descriptive statistics and the trend of adolescent childbearing assessment. For the second objective of identifying factors associated with adolescent childbearing, only adolescent women data from the most recent BDHS[14] were used. The BDHS are nationally representative surveys with samples based on a two-stage stratified sampling procedure: Enumeration areas or clusters in the first stage and households in the second stage. In sampled households, all women aged between 15 and 49 years who consent to participate in the survey are interviewed. Then $731,2,359$, and 3,859 adolescent women aged $15-19$ years were successfully interviewed during the 1987, 2010 and 2016-17 BDHS surveys respectively. Thus, the current study used three weighted samples of 731, 2,359, and 3,859 adolescent women aged 15-19 years. A detailed description of the sampling procedure for each of these three surveys is presented in the final report for each survey $[14,24,25]$.

\subsection{Variables of the study}

\subsubsection{Outcome variable}

The outcome variable of interest in this study is adolescent childbearing, which refers to the sum of the percentage of adolescents aged 15-19 who are already mothers (have had at least a live birth) and the percentage of adolescents who are pregnant with their first child at the time of the interview $[4,26]$. Thus, 
any adolescent who was already a mother or pregnant with her first child was coded one (1) and zero (0) in the opposite case.

\subsubsection{Independent variables}

Based on a prior literature review, our independent variables were classified into individual-level factors and community-level factors. The individual-level factors include: adolescent's age, education, household wealth index, working status, religion, access to mass media, age at first marriage, knowledge of any contraceptive methods, and modern contraceptive use. Community-level factors include: place of residence, health regions, community-level education, and community-level poverty. It should be noted that of the four community-level variables, two variables (community-level education, and communitylevel poverty) were created by aggregating individual-level factors (adolescent's education, and household wealth index) since these two variables are not directly found from the 2016-17 BDHS dataset.

\subsubsection{Operational definitions}

Access to mass media: Created by combining the following three variables: frequencies of listening to radio, watching TV, and reading newspapers and coded as "yes" if the adolescent was exposed to at least one of the three media and "no" in the opposite case.

Health regions: This variable had eighteen categories corresponding to the eighteen current provinces of Burundi. To reduce its excessive number of categories, it was recoded into five regions such as North Region, Central-East Region, West Region, South Region and Bujumbura Mairie[11].

Community-level education: Aggregate values measured by the proportion of adolescents with a minimum of primary level education derived from data on an adolescent's education. Then, it was categorized using national median value to values: low (communities with $<50 \%$ of adolescents have at least primary education) and high (communities with $\geq 50 \%$ of adolescents have at least primary education) community-level of adolescent education.

Community-level poverty: Aggregate values measured by the proportion of adolescents living in households classified as poorest/poorer derived from data on household wealth index. Then, it was categorized using national median value to values: low (communities with $<50 \%$ of adolescents living in poorest/poorer households) and high (communities with $\geq 50 \%$ of adolescents living in poorest/poorer households) community-level of adolescent poverty.

\subsection{Data management and Statistical analysis}

After data were extracted, recoded and reorganized, the statistical analysis was performed using STATA statistical software version 14.2. During all statistical analyses, the weighted samples were used to adjust for non-proportional sample selection and for non responses to ensure that our results were nationally representative. Frequency and percentage were used to describe the sociodemographic characteristics as well as the sexual and reproductive health history of the sample across the three surveys. The trend analysis of adolescent childbearing was evaluated using the Extended Mantel- 
Haenszel chi square test for linear trend using the OpenEpi (Version 3.01)- Dose Response program [4, 27]. A p-value $\leq 0.05$ was used to declare the existence of a significant trend.

During the BDHS data collection, two-stage stratified cluster sampling procedures were used and therefore the data were hierarchical. To obtain correct estimates in inferential analyses, advanced statistical models such as multilevel modeling that considers independent variables measured at individual- and community-levels should be used to account for the clustering effect/dependency [2831]. Thus, bivariable and multivariable multilevel logistic regression analyses were conducted to identify factors associated with adolescent childbearing by using only the most recent BDHS [14]. We first performed the bivariable multilevel logistic regression analysis to examine associations between adolescent childbearing and the selected individual and community-level variables. Then variables with a $p$-value $\leq 0.2$ in the bivariate analysis were included in the multivariable multilevel logistic regression analysis to assess the net effects of each independent variable on adolescent childbearing after adjusting for potential confounders. The fixed effects were reported in terms of adjusted odds ratios (aOR) with $95 \%$ confidence intervals $(\mathrm{Cl})$ and $p$-values. Variables with $p$-value $<0.05$ were declared to be significantly associated with adolescent childbearing in the multivariate analysis.

Before performing these multilevel logistic regression analyses, an empty model was conducted to calculate the extent of variability in adolescent childbearing between clusters (between communities). The existence of this variability was assessed using the Intra-Class correlation Coefficient (ICC) and the Median Odds Ratio (MOR) [29-32]. The ICC represents the proportion of the between-cluster variation in the total variation (the between- plus the within-Cluster variation) of the chances of adolescent childbearing $[28,29]$. It can be computed with the following formula:

\section{ICC $=\sigma^{2} /\left(\sigma^{2}+\Pi^{2} / 3\right)$}

$=\sigma^{2} /\left(\sigma^{2}+3.29\right)$, where $\sigma^{2}$ represents the cluster variance.

The MOR is the Median values of the Odds Ratio of the cluster at high risk and cluster at lower risk of adolescent childbearing when randomly picking two adolescent women from two different clusters [29, 30]. It can be computed with the following formula:

$\mathrm{MOR}=\exp \left[\sqrt{\left(2 \times \sigma^{2}\right)} \times 0.6745\right]$

$\mathrm{MOR} \cong \exp \left(0.95 \times{\sqrt{\sigma^{2}}}^{2}\right.$.

The deviance (or-2Log likelihood), Akaike Information Criteria (AIC) and Bayesian Information Criterion (BIC) were used to compare the fit to the data of the null model and that of the full model where we favored model with smaller values of these indices $[4,30,33]$.

\section{Results}




\subsection{Sociodemographic characteristics of samples}

The sociodemographic characteristics of the adolescents included in the three surveys are summarized in Table 1. The analysis of adolescents' age showed that the majority of them $(53.4 \%, 61.1 \%$ and $64.5 \%$ in the 1987, 2010 and 2016-17 BDHS respectively) were between 15 and 17 years old. Similarly, most of participants resided in rural areas: 95.7\% (1987 BDHS), 88.4\% (2010 BDHS) and 85.8\% (2016-17 BDHS). A large proportion of adolescents (75.8\% and 76.5\% in the 2010 and 2016-17 BDHS respectively) lived in three health regions (North, Central-East and South). Similarly, most adolescent girls were still single: 93.2\% (1987 BDHS), 90.2\% (2010 BDHS) and 93.3\% (2016-17 BDHS). The proportion of illiterate adolescents decreased from 73.3\% (1987 BDHS) to 7.3\% (2016-17 BDHS). On the other hand, the percentages of adolescents who were currently working increased from 7.5\% (1987 DHS) to 57.6\% (201617DHS). More than half of adolescent girls (58.5\% and 53.6\% in the 2010 and $2016-17$ BDHS surveys respectively) were from very poor/poor/middle-income households. Similarly, analysis of religious affiliation showed that most adolescents were Catholic: 61.1\% (2010 BDHS) and 55.7\% (2016-17 BDHS).

Tabble1: Sociodemographic characteristics of adolescents in Burundi using the 1987, 2010 and 2016/17 BDHS. 


\begin{tabular}{|c|c|c|c|}
\hline \multirow[t]{3}{*}{ Variables categories } & \multicolumn{3}{|l|}{ BDHS year } \\
\hline & $1987(\mathrm{~N}=731)$ & $2010(\mathrm{~N}=2359)$ & $2016-17(N=3859)$ \\
\hline & $\mathrm{n}(\%)$ & $\mathrm{n}(\%)$ & $\mathrm{n}(\%)$ \\
\hline \multicolumn{4}{|l|}{ Adolescent's Age } \\
\hline 15- 17 years & $390(53.4)$ & $1,442(61.1)$ & $2,489(64.5)$ \\
\hline 18- 19 years & $341(46.6)$ & $917(38.9)$ & $1,370(35.5)$ \\
\hline \multicolumn{4}{|l|}{ Residence } \\
\hline Rural & 700 (95.7) & $2,087(88.4)$ & $3,310(85.8)$ \\
\hline Urban & $31(4.3)$ & $273(11.6)$ & $548(14.2)$ \\
\hline \multicolumn{4}{|l|}{ Health Regions } \\
\hline Bujumbura Mairie & & $193(8.2)$ & $315(8.2)$ \\
\hline North & & $657(27.8)$ & $1,046(27.1)$ \\
\hline Central East & & $565(23.9)$ & $947(24.5)$ \\
\hline West & & $378(16.0)$ & $589(15.3)$ \\
\hline South & & $568(24.1)$ & $961(24.9)$ \\
\hline \multicolumn{4}{|l|}{ Marital Status } \\
\hline Single & $682(93.2)$ & $2,128(90.2)$ & $3,601(93.3)$ \\
\hline Married/living together & $43(5.9)$ & 201(8.5) & $227(5.9)$ \\
\hline Divorced/separated/widowed & $6(0.8)$ & $30(1.3)$ & $31(0.8)$ \\
\hline \multicolumn{4}{|l|}{ Education } \\
\hline No education & $536(73.3)$ & $500(21.2)$ & $281(7.3)$ \\
\hline Primary & $186(25.4)$ & $1,425(60.4)$ & $1,836(47.6)$ \\
\hline Secondary and above & $9(1.2)$ & $434(18.4)$ & $1,742(45.1)$ \\
\hline \multicolumn{4}{|l|}{ Currently working } \\
\hline No & 677 (92.5) & $1,112(47.1)$ & $1,634(42.4)$ \\
\hline Yes & $54(7.5)$ & 1,248 (52.9) & $2,224(57.6)$ \\
\hline \multicolumn{4}{|l|}{ Wealth Quantile } \\
\hline Poorest & & 444 (18.8) & 589 (15.3) \\
\hline Poorer & & 469 (19.9) & $711(18.4)$ \\
\hline
\end{tabular}




\begin{tabular}{|lll|} 
Middle & $468(19.8)$ & $769(19.9)$ \\
\hline Richer & $453(19.2)$ & $840(21.8)$ \\
\hline Richest & $525(22.2)$ & $950(24.6)$ \\
\hline Religion & $12(0.5)$ & $10(0.3)$ \\
\hline No religion & $1,442(61.1)$ & $2,147(55.7)$ \\
\hline Catholic & $792(33.5)$ & $1,417(36.7)$ \\
\hline Pdventist & $43(1.8)$ & $124(3.2)$ \\
\hline Muslim & $50(2.1)$ & $105(2.7)$ \\
\hline Others & $22(0.9)$ & $56(1.5)$ \\
\hline
\end{tabular}

\section{Sexual and reproductive health characteristics of the samples}

The percentage of adolescents who had their first sexual intercourse at age $\leq 14$ years increased from $0.7 \%$ (1987 BDHS) to $2.6 \%$ (2016-17 BDHS). Similarly, the percentage of adolescents who had their first birth at age $\leq 17$ years increased from 1.7\% (1987 BDHS) to 3.3\% (2016-17 BDHS). In contrast, the proportion of adolescents who had their first marriage at age $\leq 17$ decreased slightly from $4 \%$ (1987 BDHS) to $3.8 \%$ (2016-17 BDHS). Similarly, 40.1\% (1987 BDHS) of adolescents had knowledge of any contraceptive methods compared to $89.9 \%$ (2016-17 BDHS). The percentage of adolescents who do not intend to use contraception increased from 17.8\% (2010 BHDS) to 24.8\% (2016-17 BDHS). On the other hand, there was a reduction in the proportion of adolescents with unmet need for contraception, which decreased from 3.2\% (2010 BDHS) to 2.5\% (2016-17 BDHS). Regarding fertility preference, $5.8 \%$ (2010 BDHS) of adolescents wanted to have another pregnancy compared to $96.5 \%$ in the 2016-17 BDHS (See Table 2).

Table 2: Sexual and reproductive health characteristics of adolescents in Burundi using the 1987, 2010 and 2016/17 BDHS data. 
BDHS year

$\begin{array}{lll}1987 & 2010(\mathrm{~N}=2359) & \begin{array}{l}2016-17(\mathrm{~N}= \\ 3859)\end{array} \\ (\mathrm{N}=731) & \mathrm{n}(\%) & \mathrm{n}(\%)\end{array}$

Age at First Sex

$\leq 14$ years

$5(0.7)$

$83(3.5)$

$101(2.6)$

15- 17 years

$32(4.4)$

$217(9.2)$

326(8.5)

$18-19$ years

24 (3.3)

$74(3.2)$

139(3.6)

Not had sex/inconsistent/missing

$670(91.6)$

$1,985(84.1)$

$3,292(85.3)$

Age at First Marriage

$\leq 17$ years

$29(4.0)$

159 (6.7)

$148(3.8)$

$18-19$ years

$20(2.8)$

$72(3.1)$

109 (2.8)

Never in union

$682(93.2)$

$2,128(90.2)$

$3,601(93.3)$

Age at First Birth

$\leq 17$ years

$13(1.7)$

$84(3.6)$

127 (3.3)

$18-19$ years

$11(1.5)$

$74(3.1)$

107(2.8)

Still no birth

$708(96.8)$

2,201 (93.3)

$3,624(93.9)$

\section{Knowledge of Any Contraceptive Methods}

Has knowledge

No knowledge

\section{Contraceptive Use and Intention}

Using modern method

Using traditional method

Non-user - intends to use later

Does not intend to use

\section{Unmet Need for Contraception \\ (a)}

Never had sex

Unmet need for spacing/limiting

Using for spacing/liming

\begin{tabular}{lll}
$293(40.1)$ & $2,166(91.8)$ & $3,468(89.9)$ \\
\hline $438(59,9)$ & $193(8.2)$ & $390(10.1)$
\end{tabular}

$30(1.3)$

$98(2.5)$

$4(0.2)$

18(0.5)

$1,904(80.7)$

$2,785(72.2)$

421(17.8)

$958(24.8)$ 
No unmet need

$154(6.5)$

$161(4.2)$

Not married and no sex in last 30 days

$104(4.4)$

$195(5.1)$

Infecund/menopausal

$304(12.9)$

$413(10.7)$

Fertility Preference

$\begin{array}{llll}\text { Have another pregnancy } & 42(5.8) & 2,254(95.5) & 3,724(96.5) \\ \text { Undecided } & 0(0,0) & 49(2.1) & 33(0.8) \\ \text { No more } & 0(0.1) & 31(1.3) & 77(2.0) \\ \text { Declared infecund/Sterilized } & - & 24(1.0) & 25(0.7) \\ \text { Missing } & 688(94.1) & 1 .(0.1) & -\end{array}$

\section{Prevalence and trend of adolescent childbearing}

The prevalence and trend of adolescent childbearing were examined in its two components: prevalence and trend of adolescents who have had at least one live birth and prevalence and trend of those who were pregnant with their first child at the time of the survey (see figure 1). Thus, the prevalence of adolescent childbearing increased from 5.9\% (95\% Cl: 4.3 - 7.8) in 1987 to $9.6 \%$ (95\% Cl: 8.4 - 10.4) in 2010 , and then decreased from $9.6 \%$ to $8.3 \%$ (95\% Cl: 7.4 - 9.2) in 2016/17. The trend analysis shows that there was an increase of $2.4 \%$ from 1987 to $2016 / 17$ although this increase was not statistically significant $(P$-value $=0.0503)$. Indeed, the prevalence of adolescents who have had at least one live birth increased from 3.2\% (95\% Cl: 2.0 - 4.7) in 1987 to $6.7 \%$ (95\% Cl: 5.7- 7.7) in 2010, and then decreased from $6.7 \%$ to $6.1 \%$ (95\% Cl: $5.3-6.8$ ) in 2016/17. The trend analysis shows that there was an increase of $2.9 \%$ from 1987 to $2016 / 17$ and this increase was statistically significant (P-value $=0.0036)$. On the other hand, the prevalence of adolescents who were pregnant with their first child increased from $2.7 \%$ (95\% Cl: 1.7- 4.2) in 1987 to $2.9 \%$ (95\% Cl: 2.2 - 3.6) in 2010, and then decreased from 2.9 to $2.2 \%$ (95\% Cl: 1.7 2.7 ) in $2016 / 17$. The trend analysis shows that there was a decrease of $0.5 \%$ from 1987 to $2016 / 17$ but this decrease was not statistically significant $(P$-value $=0.3593)$.

\section{Determinants of adolescents childbearing.}

Bivariable and multivariable multilevel logistic regression analyses were conducted to identify individual and community-level factors associated with adolescent childbearing by using only the most recent (2016-17) BDHS data. First, an empty model was performed to calculate the extent of variability in adolescent childbearing between clusters by using the ICC and the MOR indicators. The deviance, AIC, and BIC were also used to select the model that best fit the data. The results of bivariable and multivariable analyses, random effect model and model fitness are summarized in table $\mathbf{3}$. 
According to the findings in table 3, the ICC of the empty model was estimated to 20.2, which indicated that about $20.2 \%$ of the variations in adolescent childbearing were attributable to community differences. Similarly, the MOR of the empty model was estimated to 2.37 , which means that if we randomly selected two adolescent girls from two different communities, the one from a higher risk community had 2.37 times higher odds of childbearing than the one from a lower risk community. The model fitness findings revealed the best-fitted model was the full model (model with individual and community-level factors) since it had significantly $(p<0.001)$ lower values of deviance (905.70), AIC (955.71), and BIC (1112.16) compared to those of the empty model. In the bivariable analysis, factors like adolescent's age, education, working status, household wealth index, religion, access to mass media, age at first marriage, knowledge of any contraceptive methods, modern contraceptive use, health regions and community-level poverty met the minimum criteria $(p \leq 0.2)$ to be included in the multivariable analysis.

In the multivariable analysis, only factors such as adolescent's age, adolescent's education, household wealth index, age at first marriage, knowledge of any contraceptive methods, modern contraceptive use, health regions, and community-level poverty remained significantly associated with adolescent childbearing. Indeed, adolescents aged 18-19 years had about 6 times higher odds (aOR $=5.85,95 \% \mathrm{Cl}: 3.54-9.65, \mathrm{p}<0.001)$ of childbearing than those aged 15-17 years. The odds of childbearing among adolescents who had no education was about 4 times higher $(\mathrm{aOR}=4.18,95 \% \mathrm{Cl}$ : $1.88-9.30, p<0.001)$, and those who had only a primary education was about 2 times higher $(\mathrm{aOR}=2.58$, $95 \% \mathrm{Cl}: 1.54-4.25, \mathrm{p}<0.001)$ than adolescents who had a secondary or high education. The adolescents in the richest household quintile had $48 \%$ lower odds ( $a O R=0.52,95 \%$ IC: $0.45-0.87, p=0.007$ ) of childbearing compared to those in the poorest household quintile.

Similarly, the odds of childbearing among adolescents who got married at $\leq 17$ years old was about 9 times higher $(\mathrm{aOR}=9.28,95 \% \mathrm{Cl}: 3.11-27.65, \mathrm{p}<0.001)$ than those who got married at the age between 18 and 19. Moreover, the adolescents who didn't have knowledge of any contraceptive methods had about 5 times higher odds ( $\mathrm{aOR}=5.33,95 \% \mathrm{Cl}$ : $1.48-19.16, \mathrm{p}=0.010)$ of childbearing than those who had knowledge of any contraceptive methods. Similarly, the odds of childbearing among adolescents who were not using modern contraceptive methods was about 24 times higher $(\mathrm{aOR}=24.48$, $95 \% \mathrm{Cl}: 9.80$ - 61.14), $\mathrm{p}<0.001)$ than those who were using modern contraceptive methods. Also, the odds of childbearing among adolescents living in West, and those in South were about $74 \%$ (aOR= 0.26 , $95 \% \mathrm{Cl}: 0.08-0.86), p=0.027)$ and $69 \%(a \mathrm{R}=0.31,95 \% \mathrm{Cl}: 0.10-0.96, p=0.041)$ times lower respectively than those living in Bujumbura Mairie. Finally, the odds of childbearing among adolescents living in high community-level poverty was about 2 times higher (aOR=2.19, 95\% Cl: $1.03-4.64, p=0.042)$ than those living in low community-level poverty.

Table3: Results of bivariable and multivariable multilevel logistic regression analyses of factors associated with adolescent childbearing in Burundi. 
2016-17 BDHS (weighted sample, $\mathrm{N}=3859$ )

Variables/categories

Bivariable analysis

UOR $(95 \% \mathrm{Cl})$

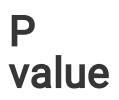

Multivariable analysis aOR $(95 \% \mathrm{Cl}) \quad \mathrm{P}$ value

$\mathrm{P}$
value

Individual-level variables

Adolescent's age

15- 17 years $(R C)$

18- 19 years
1.00

$13.87(9.93-$

19.38)
1.00

$2.71(2.02-3.64)$

Primary

No education

$5.79(3.80-8.80)$

Secondary /High (RC)

$<$

0.001

1.00

5.85 (3.54 9.65)$$
\text { 9.65) }
$$
$<0.001$

\section{Education}

0.001 


\begin{tabular}{|c|c|c|c|c|}
\hline Adventist & $\begin{array}{l}0.60(0.11- \\
3.30)\end{array}$ & 0.559 & $\begin{array}{l}3.25(0.02- \\
653.55)\end{array}$ & 0.663 \\
\hline Muslim & $\begin{array}{l}0.40(0.07- \\
2.27)\end{array}$ & 0.303 & $\begin{array}{l}10.55(0.06- \\
2016.49)\end{array}$ & 0.379 \\
\hline Others & $\begin{array}{l}0.44(0.07- \\
2.73)\end{array}$ & 0.381 & $\begin{array}{l}4.22(0.02- \\
960.45)\end{array}$ & 0.603 \\
\hline
\end{tabular}

Access to Mass Media

No Access(RC)

1.00

1.00

Has Access

$\begin{array}{llll}0.65(0.51- & 0.001 & 0.67(0.43-1.06) & 0.090 \\ 0.84) & & & \end{array}$

Age at First Marriage

$18-19$ years $(\mathrm{RC})$

1.00

1.00

$\leq 17$ years

$9.66(3.57$

26.11)

$<0.001$

$9.28(3.11-$

$<0.001$

Never in union (NA)

) $0.00(0.00-0.01<0.001$

27.65)

$0.01(0.00-\quad<0.001$

Knowledge of Any Contraceptive $\quad 1.00$

Methods

Has Knowledge (RC)

1.00

1.00

No Knowledge

$9.86(3.82-$

25.44)

$\begin{array}{ll}< & 5.33(1.48- \\ 0.001 & 19.16)\end{array}$

0.010

Modern Contraceptive Use

Yes (RC)

1.00

1.00

No

$35.17(21.03-$

$<$

58.79)

0.001

$24.48(9.80-$ $<0.001$

\section{Community-Level Variables}

\section{Place of Residence}

Rural (RC)

1.00

Urban
$1.17(0.77-$
1.78)
0.456

\section{Health Regions}

Bujumbura Mairie

1.00

1.00

North

$0.96(0.54-$

1.70)

0.887

$0.46(0.14-1.44)$

0.182

Central East

$0.56(0.31-\quad 0.058$

$0.34(0.11-1.05)$

0.062 
West
$0.83(0.44-$
1.54)
0.546
$0.26(0.08-$

0.027

South
$0.44(0.24-$
$0.81)$
0.008
$0.31(0.10-$

0.041

Community-level Education

Low (RC)

1.00

High
$0.88(0.60-$
1.27)
0.491

\section{Community-level Poverty}

\begin{tabular}{|c|c|c|c|c|}
\hline Low (RC) & 1.00 & & 1.00 & \\
\hline High & $1.31(0.97-1.78)$ & 0.083 & $2.19(1.03-4.64)$ & 0.042 \\
\hline Random effect & Empty model & & Full model & \\
\hline Community variance (SE) & $0.83(0.20)$ & & $0.62(0.14)$ & \\
\hline ICC (\%) & 20.2 & & 15.8 & \\
\hline MOR & 2.37 & & 2.11 & \\
\hline \multicolumn{5}{|l|}{ Model fitness } \\
\hline Log likelihood & -1079.61 & & -452.85 & \\
\hline Deviance & 2159.22 & & 905.70 & \\
\hline AIC & 2163.22 & & 955.71 & \\
\hline $\mathrm{BIC}$ & 2175.74 & & 1112.16 & \\
\hline Clusters & 553 & & 553 & \\
\hline
\end{tabular}

Note: AIC: Akaike's Information Criterion, BIC: Bayesian Information Criterion, ICC: Intra-Cluster Correlation, MOR: Median Odds Ratio, SE: Standard Error, uOR: Unadjusted Odd Ratio, aOR: Adjusted Odd Ratio.

\section{Discussion}

This study aimed to analyze the prevalence, trend and determinants of adolescent childbearing in Burundi using data from the three DHS conducted in Burundi in 1987[25], 2010[24], and 2016-17[14] respectively. Our findings showed that the prevalence of adolescent childbearing increased from $5.9 \%$ in 1987 to $8.3 \%$ in $2016 / 17$. This upward trend in adolescent childbearing could be attributed to a significant increase in cases of unintended pregnancies especially among schoolgirls in Burundi in one hand[21, 23, 34], and to difficulties in accessing/low use of family planning services by adolescent girls in Burundi on the other hand[23,35,36]. Although this upward trend in adolescent childbearing was not 
statistically significant, Burundi should make greater efforts to reverse this trend given the negative impact of adolescent childbearing in Burundi on the young mothers and their babies' well-being[21, 37, $38]$ and on the current demographic pressure[11, 13]. Moreover, several studies showed that the high level of maternal and infant morbidity and mortality can be reduced by reducing the adolescent childbearing rates in developing countries $[3,39,40]$. In addition, Burundi should take as a good example most of its neighboring countries that are currently showing a downward trend in adolescent childbearing after having made enormous efforts $[4,7]$.

Our study identified some key determinants of adolescent childbearing in the Burundian settings. Indeed, our findings indicated that adolescents aged 18-19 years were more likely to start childbearing than those aged 15-17 years. This positive correlation between adolescent age and risk of childbearing could be explained by increased exposure to sexual intercourse and marriage as the age of adolescent increases $[4,10]$. Our results are consistent with those of many previous studies $[4,7,10]$ that showed that the odd of adolescent pregnancy increases with adolescent age. This finding highlights the adolescent's age group that should be targeted more when designing programs to reduce/prevent adolescent childbearing in Burundi. Similarly, our results showed that adolescents who had no education were more likely to start childbearing than those who had a secondary or high education. Such an association could be explained by the fact that out-of-school adolescent girls do not have access to comprehensive sexuality education[41] and skills necessary to negotiate sexuality and reproductive options [3]. The protective effect of education against adolescent childbearing has also been reported in several previous studies. Indeed, adolescents who had no education had about 2 times higher odds of childbearing compared to those who were in school[3]. Teenage girls who had no education had about 3 times higher odds of childbearing than those who had a secondary or high education[41]. Other similar results were reported in studies conducted in Malawi[10], and in five East African countries[7]. In Burundi, a significant increase in the school attendance rate, especially at the primary level, was observed following the implementation of the free schooling policy at the primary level initiated by the Burundian government since 2005[42]. However, there is still a gender gap in school attendance, especially at the secondary level[14]. Given the importance of education, particularly at the secondary and tertiary levels, in preventing teenage childbearing, policymakers should do everything possible to promote young girls education at all levels of the Burundian education system while incorporating comprehensive sexuality education[43].

Our findings also revealed that household poverty or living in poor communities is associated with higher odds of adolescent childbearing. In the Burundian context, this association could be explained by the fact that household poverty exposes Burundian adolescent girls to early sexual intercourse in exchange for money, and consequently to a higher risk of early and unwanted pregnancies[13, 22]. Our results corroborate those of the study by Vikat et al. [44] and those of the study by Kearney and his colleague [45]. Although the relationship between poverty and adolescent childbearing may be a vicious cycle [3], our findings and available evidence[7, 9, 13] underscore the importance of improving the households' socioeconomic status in general, but especially of disadvantaged communities, to reduce the prevalence of adolescent childbearing, thereby improving their sexual and reproductive health. This study also found that the adolescent early marriage is associated with a higher odd of childbearing. This link between early 
marriage and higher risk of adolescent childbearing could be justified by the fact that early marriage implies early sexual debut and therefore a major risk of early pregnancy and childbearing $[7,9,46]$. In addition, several previous studies $[3,4,9,46]$ reported similar results. In Burundi, early marriage is associated with not only young mothers' and their babies' poor health outcomes [14], but also with high fertility rate[11]. While the official age of marriage for girls in Burundi is 18, early marriage remains a common practice, especially in rural areas. Thus, the Burundian government should ensure the strict enforcement of any law aimed at combating early marriage. Indeed, apart from the findings of our study, several other researchers $[3,4,43,46]$ suggest that investing in the prevention of child marriage is important not only to reduce teenage pregnancies and related complications, but also to improve a country's economic development.

Similarly, our findings showed that both the lack of knowledge of any contraceptive methods and the non-use of modern contraceptive methods were associated with higher odds of adolescent childbearing. The positive influence of good knowledge and use of family planning services in preventing or reducing the rate of unintended pregnancies among adolescent girls has been widely reported in the scientific literature $[9,10,37,46]$. However, most Burundian adolescent girls do not use contraception, and some do not even plan to use it in the future [14]. Indeed, the prevalence of contraceptive use among adolescent girls remains very low $(2.5 \%)$ and the percentage of adolescents girls who do not intend to use contraception increased from $17.8 \%$ in 2010 to $24.8 \%$ in 2016-17. Moreover, the percentage of adolescents who had knowledge of any contraceptive methods decreased from $91.8 \%$ in 2010 to $89.9 \%$ in 2016-17[14, 24]. The results of this study as well as the available evidence[43, 46] highlight the importance of interventions such as sexuality and health education at all levels of the Burundian education system and provision of contraceptive services to adolescents and creating supportive environments to reduce the prevalence of adolescent childbearing in Burundi.

The strength of our study is that it would be among the first to focus on trend analyses and communitylevel factors in the analysis of determinants of adolescent childbearing in Burundi. In addition, this study is the first to use an advanced logistic regression model (multilevel model) to identify the determinants of adolescent childbearing in Burundi. However, our study also suffers from some limitations. The 1987 DHS database did not contain some of the variables of interest to our study. Therefore, we limited ourselves to the analysis of the available variables. Moreover, our study looked only at current pregnancies or previous births of adolescents to assess the prevalence of adolescent childbearing and did not consider adolescent pregnancies that ended in miscarriage, abortion, or stillbirth. This consideration is very important in the interpretation of the results of this study by readers, as there may be an underestimation bias in the prevalence. Indeed, given the Burundian culture, which still considers pregnancy outside of marriage to be a disgrace to the family[21], many cases of induced and clandestine abortion are quite possible in Burundi, as was found in two recent studies conducted in two of Burundi's neighboring countries, in Uganda [47] and in Ethiopia[48], which showed that nearly one in six adolescent pregnancies ends in an induced and clandestine abortion. Further studies that include adolescent pregnancies that ended in miscarriage, abortion, or stillbirth in prevalence estimate are needed to better understand the extent of the problem in Burundi. 


\section{Conclusion}

The prevalence of adolescent childbearing increased from $5.9 \%$ in 1987 to $8.3 \%$ in 2016/17 although this increase was not statistically significant. There were variations in the odds of adolescent childbearing by some individual and community-level factors. Factors such as late adolescent age, adolescent illiteracy, household poverty or high community-level poverty, early marriage, lack of knowledge of any contraceptive methods, non-use of modern contraceptive methods, and living in Bujumbura Mairie were associated with higher odds of adolescent childbearing. School- and community- based intervention programs aimed at promoting girls' education and improving socioeconomic status, knowledge and utilization of contraceptives and prevention of early marriage among adolescent girls is crucial to reduce adolescent childbearing in Burundi.

\section{Abbreviations}

- AIC: Akaike Information Criteria

- aOR: Adjusted Odd Ratio

- BDHS : Burundi Demographic and Health Survey

- BIC: Bayesian Information Criterion

- ICC :Intra-Class correlation Coefficient

- MOR: Median Odds Ratio

- SSA: Sub-Saharan Africa

- WHO: World Health Organization

\section{Declarations}

\section{Ethics approval and consent to participate}

The 1987, 2010, and 2016-17 survey protocols, consent forms, and data collection instruments were reviewed and approved by the National Ethics Committee for the Protection of Human Beings Participating in Biomedical and Behavioral Research in Burundi and the Institutional Review Board of ICF International. In addition, data were collected after informed consent was obtained from the participants and all information was kept confidential. For this study, permission was given by the MEASURE DHS program to access and download the three datasets after reviewing a short summary of this study submitted to the MEASURE DHS program via its website [49]. All the three datasets were treated with confidentiality.

\section{Consent for publication}

Not Applicable 
The data that support the findings of this study are available for download upon a formal application from the DHS Program web site https://dhsprogram.com/data/availabledatasets.cfm, but restrictions apply to the availability of these data, which were used under license for the current study, and so are not publicly available. Data are however available from the authors upon reasonable request and with permission of the DHS Program.

\section{Competing interests}

The authors declare that they have no competing interests

\section{Funding}

This study is financed by the Burundian government through the scholarship granted to Mr. Jean Claude Nibaruta under contract No.611/BBES/0134/12/2017/2018 within the framework of his PhD studies in Morocco. The funders had no role in study design, data collection and analysis, decision to publish, or preparation of this manuscript.

\section{Authors' contributions}

JCN and NK conceived the idea and design and contributed in data analysis, interpretation of results, discussion and manuscript drafting. MG substantively contributed in discussion and manuscript drafting. SM was a major contributor in data analysis and interpretation of results. While JET advised on data analysis and substantively revised the manuscript. All authors read and approved the final manuscript.

\section{Acknowledgments}

We extend our sincere thanks to the Measure DHS program for granting permission to access and use the 1987, 2010 and 2016/17 BDHS data for this study.

\section{References}

1. World Health Organization. Guidance on ethical considerations in planning and reviewing research studies on sexual and reproductive.pdf. Geneva: WHO; 2018.

2. Plummer ML, Baltag V, Strong K, Dick B, Ross DA. World Health Organization, et al. Global Accelerated Action for the Health of Adolescents (AA-HA!): guidance to support country implementation [Internet]. 2017 [cited 2020 Feb 19]. Available from: http://apps.who.int/iris/bitstream/10665/255415/1/9789241512343-eng.pdf.

3. Kassa GM, Arowojolu AO, Odukogbe AA, Yalew AW. Prevalence and determinants of adolescent pregnancy in Africa: a systematic review and Meta-analysis. Reprod Health. 2018;15:195.

4. Kassa GM, Arowojolu AO, Odukogbe A-TA, Yalew AW. Trends and determinants of teenage childbearing in Ethiopia: evidence from the 2000 to 2016 demographic and health surveys. Ital $\mathrm{J}$ 
Pediatr. 2019;45:153.

5. World Bank Group. Global monitoring report 2015/2016: Development goals in an era of demographic change. The World Bank; 2015.

6. United Nations, Department of Economic and Social Affairs, Population Division. (2020). World Fertility 2019: Early and later childbearing among adolescent women (ST/ESA/SER.A/446). [Internet]. [Cited 2021 Jan 13]. Available from: https://www.un.org/en/development/desa/population/publications/index.asp.

7. Wado YD, Sully EA, Mumah JN. Pregnancy and early motherhood among adolescents in five East African countries: a multi-level analysis of risk and protective factors. BMC pregnancy and childbirth. Springer; 2019; 19:59.

8. World Health Organization. Adolescent pregnancy [Internet]. [cited 2021 Jan 12]. Available from: https://www.who.int/news-room/fact-sheets/detail/adolescent-pregnancy.

9. World Health Organization. Adolescent pregnancy situation in South-East Asia region. WHO Regional Office for South-East Asia; 2015.

10. Palamuleni ME. Determinants of adolescent fertility in Malawi. Gender and Behaviour. 15: IFE Centre for Psychological Studies (ICPS); 2017. pp. 10126-41.

11. Nibaruta JC, Elkhoudri N, Chahboune M, Chebabe M, Elmadani S, Baali A, et al. Determinants of fertility differentials in Burundi: evidence from the 2016-17 Burundi demographic and health survey. PAMJ [Internet]. 2021 [cited 2021 Apr 2]; 38. Available from: https://www.panafrican-medjournal.com/content/article/38/316/full.

12. Islam MM. Adolescent childbearing in Bangladesh. Asia Pacific Population Journal. 14: ECONOMIC AND SOCIAL COMMISSION FOR ASIA AND THE PACIFIC; 1999. pp. 73-87.

13. Rasmussen B, Sheehan P, Sweeny K, Symons J, Maharaj N, Kumnick M, et al. Adolescent Investment Case Burundi. Estimating the Impacts of Social Sector Investments for Adolescents. UNICEF; 2019.

14. Ministère à la Présidence chargé de la Bonne Gouvernance et du Plan (MPBGP), Ministère de la Santé Publique et de la Lutte Contre le Sida(MSPLS), Institut de Statistiques et d’Études Économiques du Burundi (ISTEEBU), ICF. Troisième Enquête Démographique et de Santé 2016-2017 [Internet]. Bujumbura, Burundi: ISTEEBU, MSPLS, and ICF.; 2017 Dec p. 679. Available from: https://dhsprogram.com/publications/publication-FR335-DHS-Final-Reports.cfm.

15. Kalaivani K. Prevalence \& consequences of anaemia in pregnancy. Indian J Med Res Citeseer. 2009;130:627-33.

16. Ahmad MO, Kalsoom U, Sughra U, Hadi U, Imran M. Effect of maternal anaemia on birth weight. Journal of Ayub Medical College Abbottabad. 2011;23:77-9.

17. Vikat A, Rimpelä A, Kosunen E, Rimpelä M. Sociodemographic differences in the occurrence of teenage pregnancies in Finland in 1987-1998: a follow up study. Journal of Epidemiology \& Community Health. BMJ Publishing Group Ltd; 2002; 56:659-68.

18. Kearney MS, Levine PB. Why is the teen birth rate in the United States so high and why does it matter? Journal of Economic Perspectives. 2012;26:141-63. 
19. Gideon R. Factors associated with adolescent pregnancy and fertility in Uganda: analysis of the 2011 demographic and health survey data. American Journal of Sociological Research. 2013;3:305.

20. Neal S, Ruktanonchai C, Chandra-Mouli V, Matthews Z, Tatem AJ. Mapping adolescent first births within three east African countries using data from Demographic and Health Surveys: exploring geospatial methods to inform policy. Reproductive health BioMed Central. 2016;13:1-29.

21. Ruzibiza Y. 'They are a shame to the community... stigma, school attendance, solitude and resilience among pregnant teenagers and teenage mothers in Mahama refugee camp, Rwanda. Global public health. Taylor \& Francis; 2020. pp. 1-12.

22. Munezero D, Bigirimana J. Jont program" Menyumenyeshe" for improving sexual and reproductive health of adolescents and youth in Burundi [Internet]. Bujumbura, Burundi: Ministry of Public health and for fighting against Aids; 2017 p. 120. Available from:

http://www.careevaluations.org/evaluation/improving-sexual-and-reproductive-health-ofadolescents-and-youth-in-burundi/.

23. French H. How the "Joint Program" Intervention Should or Might Improve Adolescent Pregnancy in Burundi, How These Potential Effects Could Be Encouraged, and Where. Caution Should Be Given; 2019.

24. Institut de Statistiques et d'Études Économiques du Burundi (ISTEEBU), Ministère de la Santé Publique et de la Lutte, contre le Sida (MSPLS), ICF International. Enquête Démographique et de Santé 2010 [Internet]. Bujumbura, Burundi: ISTEEBU, MSPLS, et ICF International.; 2012 May p. 419. Available from: https://dhsprogram.com/publications/publication-FR253-DHS-Final-Reports.cfm.

25. Segamba L, Ndikumasabo V, Makinson C, Ayad M. Enquête Démographique et de Santé au Burundi 1987 [Internet]. Columbia, Maryland, USA: Ministère de l'Intérieur Département de la Population/Burundi and Institute for Resource Development/Westinghouse; 1988 Oct. p. 385. Available from: https://dhsprogram.com/publications/publication-FR6-DHS-Final-Reports.cfm.

26. Croft TN, Marshall AM, Allen CK, Arnold F, Assaf S, Balian S. Guide to DHS statistics. Rockville: ICF. $2018 ; 645$.

27. Dean AG, Sullivan KM, Soe MM. OpenEpi: open source epidemiologic statistics for public health, version 3.01. www.OpenEpi.com, updated 2013/04/06. 2013; Available from: http://www.openepi.com/DoseResponse/DoseResponse.htm.

28. Sommet N, Morselli D. Keep Calm and Learn Multilevel Logistic Modeling: A Simplified Three-Step Procedure Using Stata, R, Mplus, and SPSS. International Review of Social Psychology. 2017;30:203-18.

29. Merlo J, Chaix B, Ohlsson H, Beckman A, Johnell K, Hjerpe P, et al. A brief conceptual tutorial of multilevel analysis in social epidemiology: using measures of clustering in multilevel logistic regression to investigate contextual phenomena. J Epidemiol Community Health. 2006;60:290-7.

30. Tesema GA, Worku MG. Individual-and community-level determinants of neonatal mortality in the emerging regions of Ethiopia: a multilevel mixed-effect analysis. BMC Pregnancy Childbirth. 
2021;21:12.

31. Teshale AB, Tesema GA. Determinants of births protected against neonatal tetanus in Ethiopia: $A$ multilevel analysis using EDHS 2016 data. Das JK, editor. PLoS ONE. 2020; 15:e0243071.

32. Tessema ZT, Tamirat KS. Determinants of high-risk fertility behavior among reproductive-age women in Ethiopia using the recent Ethiopian Demographic Health Survey: a multilevel analysis. Tropical Medicine Health BioMed Central. 2020;48:1-9.

33. Heck RH, Thomas S, Tabata L. Multilevel modeling of categorical outcomes using IBM SPSS [Internet]. Routledge Academic; 2013. Available from: https://books.google.fr/books? id=PJsTMAuPv6kC\&hl=fr\&source=gbs_book_other_versions.

34. Manishatse L. 8\% of adolescent girls fell pregnant in Burundi, reveals ISTEEBU report [Internet]. IWACU English News. 2018 [cited 2021 May 18]. Available from: https://www.iwacuburundi.org/englishnews/8-of-adolescent-girls-fell-pregnant-in-burundi-reveals-isteebu-report/.

35. Westeneng J, Reis R, Berkmoes LH. The effectiveness of sexual and reproductive health education in Burundi: policy brief. Unesco: Health and Education Resource Centre; 2020.

36. Nzokirishaka A, Itua I. Determinants of unmet need for family planning among married women of reproductive age in Burundi: a cross-sectional study. Contracept Reprod Med. 2018;3:11.

37. Hindin MJ, Kalamar AM, Thompson T, Upadhyay UD. Interventions to prevent unintended and repeat pregnancy among young people in low-and middle-income countries: a systematic review of the published and gray literature. Journal of adolescent health Elsevier. 2016;59:8-15.

38. Sommers M. Adolescents and violence: Lessons from Burundi. Institute of Development and Policy Management-University of Antwerp Discussion Paper. 2013; 2.

39. Nove A, Matthews Z, Neal S, Camacho AV. Maternal mortality in adolescents compared with women of other ages: evidence from 144 countries. The Lancet Global Health Elsevier. 2014;2:e155-64.

40. Olausson PO, Cnattingius S, Haglund B. Teenage pregnancies and risk of late fetal death and infant mortality. BJOG: An International Journal of Obstetrics Gynaecology Wiley Online Library. 1999;106:116-21.

41. Islam MM, Islam MdK, Hasan MS, Hossain MB. Adolescent motherhood in Bangladesh: Trends and determinants. Khan HTA, editor. PLoS ONE. 2017;12:e0188294.

42. Cieslik K, Giani M, Munoz Mora JC, Ngenzebuke RL, Verwimp P. Inequality in Education, Schooldropout and Adolescent lives in Burundi. Brussels: UNICEF-Burundi/Université Libre de Bruxelles; 2014.

43. World Health Organization. WHO recommendations on adolescent sexual and reproductive health and rights. World Health Organization; 2018.

44. Vikat A, Rimpelä A, Kosunen E, Rimpelä M. Sociodemographic differences in the occurrence of teenage pregnancies in Finland in 1987-1998: a follow up study. Journal of Epidemiology \& Community Health. BMJ Publishing Group Ltd; 2002;56:659-68. 
45. Kearney MS, Levine PB. Why is the teen birth rate in the United States so high and why does it matter? Journal of Economic Perspectives. 2012;26:141-63.

46. World Health Organization. Preventing early pregnancy and poor reproductive outcomes among adolescents in developing countries: What the evidence says. World Health Organization; 2012.

47. Sully EA, Atuyambe L, Bukenya J, Whitehead HS, Blades N, Bankole A. Estimating abortion incidence among adolescents and differences in postabortion care by age: a cross-sectional study of postabortion care patients in Uganda. Contraception Elsevier. 2018;98:510-6.

48. Sully E, Dibaba Y, Fetters T, Blades N, Bankole A. Playing it safe: legal and clandestine abortions among adolescents in Ethiopia. Journal of Adolescent Health. Elsevier; 2018; 62:729-36.

49. DHS Program. The DHS Program - Request Access To Datasets [Internet]. The Demographic and health surveys Program. [cited 2020 Apr 21]. Available from: https://dhsprogram.com/data/newuser-registration.cfm.

\section{Figures}

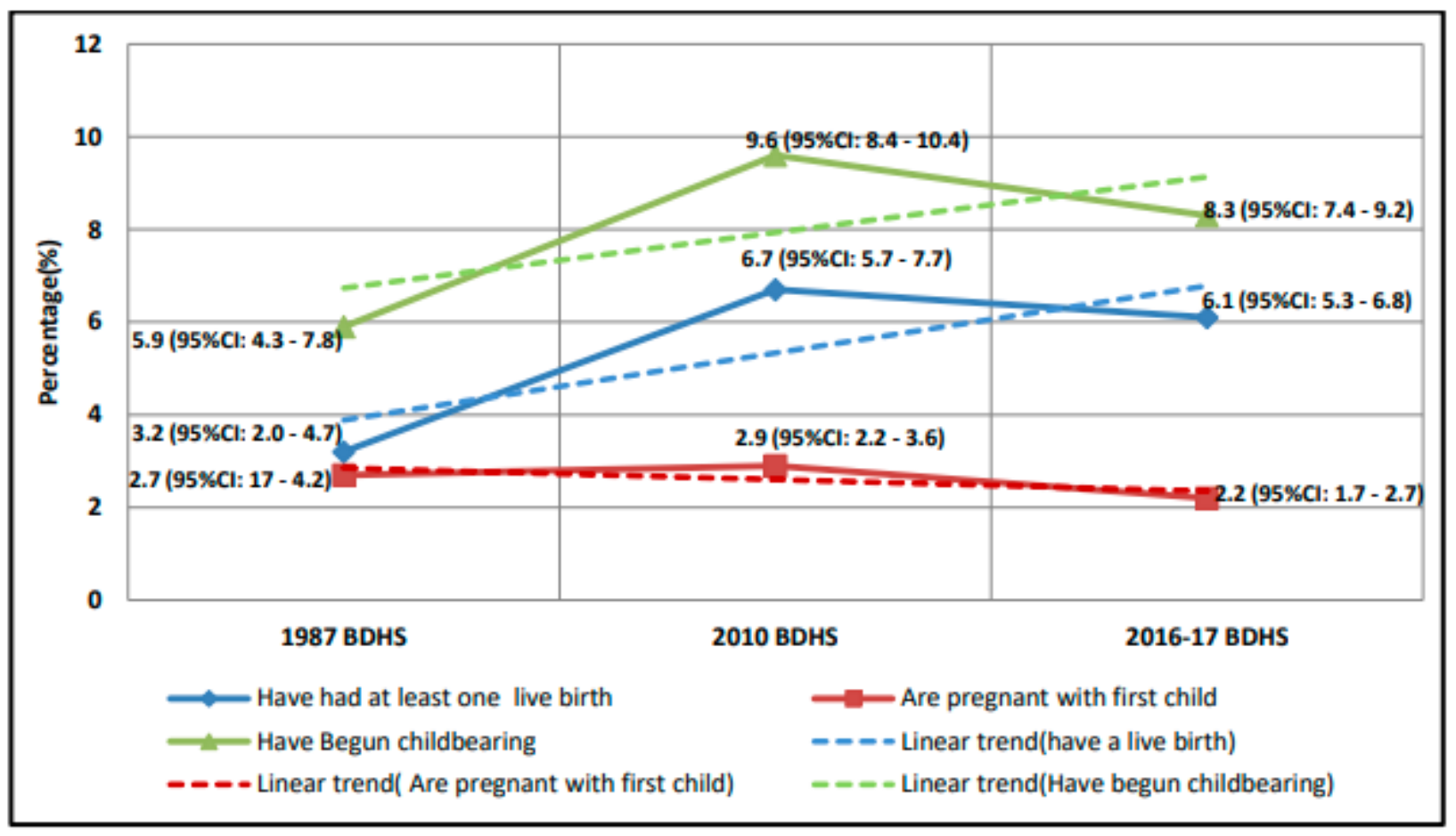

\section{Figure 1}

Prevalence and trend of adolescent childbearing in Burundi using the 1987, 2010 and 2016-17 BDHS Data.

\section{Supplementary Files}


This is a list of supplementary files associated with this preprint. Click to download.

- STROBEchecklistv4crosssectional.pdf 